\title{
The Exploration on Relief Mechanism of Anti-domestic Violence Law of People's Republic of China
}

\author{
$\mathrm{Ma} \mathrm{Hui}^{1 *}$, Zhang Yanqiu ${ }^{2}$ \\ ${ }^{1}$ College of Arts and Law of Wuhan University of Technology, Wuhan Hubei,China \\ ${ }^{2}$ College of Arts and Law of Wuhan University of Technology, Wuhan Hubei,China \\ *email:15977440@qq.com
}

\begin{abstract}
On March 1st, 2016, Anti-domestic Violence Law of People's Republic of China was officially come into force. This is China's first specialized law that focuses on anti-domestic violence. The essay analyses the four characteristics of the Law's relief mechanism, namely mechanisms of the personal safety protective order, the caution letter issued by public security organs, the compulsory reporting, and the disqualification from guardianship. The law makes it clear that it is a shared responsibility for the state, society and every family to fight against domestic violence.
\end{abstract}

Key words: Domestic violence; personal safety protective order; compulsory reporting

\section{The definition of the party of domestic violence}

In accordance with the Article 2 and Article 37 of the Law ${ }^{\circledR}$, it provides that there are two types of the party of domestic violence: family members and those persons living together who are not family members.

\subsection{Family Members}

In terms of sociology, family members refer to spouses, parents, offspring and other close family members who live with them. Legally, there's no specific definition on family members. Based on the interpretation of "family connections"in the Chapter 3 of Marriage Law of People's Republic of China, family members are close relatives including spouses, parents, offspring, siblings, and paternal or maternal grand-parents. In the real life, when one couple have a fight, it may involve parents of each other and other family members. In practice, the violence happening with the affinity will also be deemed as domestic violence. ${ }^{[1]}$ Therefore, the author believes that it will have limitations in Anti-domestic Violence Law if family members are only defined as close relatives including spouses, parents, offspring, siblings, and grand-parents. The definition should also include persons with fictional blood relationship and the affinities (such as daughter-in-law and parents-in-law and son-in-law and parents-in-law).

\subsection{Persons living together who are not family members}

In Anti-domestic Violence Law, Article 37 provides that persons living together who are not family members should also be included into the party of domestic violence. In this case, living together means non-family members live together because of some kinds of special emotional ties or the legal relationship that is similar to family members. It includes non-marital cohabitation, the relationship of guardianship, support, fosterage. Meanwhile, it should also include persons such as ex-spouses who have a close relationship with the one commits domestic violence. Even if they are non-family members, their relationship is close and dependent. The violence happening between them shares the similar characteristics with that happening between family members. For example, the violent behavior is elusive

(1)Anti-domestic Violence Law Article2: "Domestic violence" means the inflicting of physical, psychological or other harm by a family member on another by beating, trussing, injury, restraint and forcible limits on personal freedom, recurring verbal abuse, threats and other means.

Article 37:This Law shall apply, mutates mutandis, to the violence inflicted between those living together who are not family members. 
and will happen again and again; the intention of the perpetrator is often to control the other party ${ }^{[2]}$. The author believes that it conforms to the legislative intention to have these people under the auspices of Anti-domestic Violent Law, which also takes China's social practice into consideration.

\section{The Definition of Types of Domestic Violence}

In accordance with the Article 2 of Anti-domestic Violence Law, domestic violence falls into two categories: physical violence and psychological violence.

\subsection{Physical Violence}

Physical violence is the commonest and major means of committing domestic violence. In the Article 2 of the Law, it provides that "domestic violence" means the inflicting of physical, psychological or other harm by a family member on another by beating, trussing, injury, restraint and forcible limits on personal freedom, recurring verbal abuse, threats and other means. Physical violence inflicts on the victim's flesh directly, causing hurts to the victim to a varying degree. The victim will also suffer from severe psychological issues, such as fearless and depression. The hurt caused by physical violence is easily found by others. When it is severe, the victim may go to the hospital, which is easier to verify the domestic violence and assess severity. The evidence will in the victim's favor. In this regard, the violence is more likely to be stopped.

\subsection{Psychological Violence}

The Anti-domestic Violence Law distinguishes the psychological violence into two types: recurring verbal abuse and threats. In reality, the means of psychological violence is far more than these, for instance cold violence. Some scholars believe that stopping having sex with the partner is also one of the kinds of cold violence ${ }^{[3]}$. Certainly, the psychological suffering caused by physical violence is also defined as psychological violence. Although it seems that suffering psychologically is not as severe as that physically, the damage caused by psychological violence is far more serious than the physical one. In some cases, the serious psychological violence may lead to suicide or other disastrous results.

Compared with physical violence, psychological violence is more difficult to detect or assess. Even so, it is still necessary to take it as one of domestic violence types. It is not only an international general practice, but the need arising from social reality. By doing so, the rights of the victim can be protected as much as possible.

\section{The Relief Mechanism of Anti-domestic Violence Law}

\subsection{The Mechanism of the Personal Safety Protective Order}

The mechanism of the personal safety protective order is the most effective legal means internationally to prevent domestic violence. In Anti-domestic Violence Law, Article 23 to 32 has made detailed provisions on the personal safety protective order, including application eligibility, applicant, application method, retro-activity and legal force of the court exercising jurisdiction. Dated back to 2008, China has piloted the mechanism of the personal safety protective order in some areas and the feedback was good. However, there are still many limitations. For instance, the victim cannot apply for the personal safety protective order independently. This mechanism is closely connected with other legal relationship such as marriage or heritage. ${ }^{[4]}$ The victim must file a lawsuit over divorce, support or heritage within 30 days after the application of the personal safety protective order. Otherwise, the court will revoke its rulings on the personal safety order. The personal safety order connected with divorce, support or heritage cannot protect the legitimate rights of the victim. The Anti-domestic Violence Law overcomes this limitation and provides that application can be lodged in duration of the legal relationship such as 
marriage or heritage. The application can be made without the condition of filing a lawsuit over divorce, support or heritage. The enforcement of the personal safety protective order will mainly rely on people's court. The public security organ, the residents' committee or the villagers' committee will play a supportive role. Therefore, the enforcement of the ruling is more stringent than the previous. ${ }^{[5]}$

The purpose of the personal safety protective order is to prevent rather than punish. It cannot eliminate domestic violence completely. Yet the intervention of great public rights, the enforcement of party, will build a legal protective screen for victims, which will play a big role in protecting victim's dignity and safety.

\subsection{The Mechanism of the Public Security Organ's Caution Letter}

In Anti-domestic Violence Law, Article16 and Article17 ${ }^{11}$ make detailed provisions on the mechanism of the caution letter issued by public security organs, including the content of the caution letter, and the specific role of the residents' committee and the villagers' committee. The essence of this mechanism is the administrative guidance given by law enforcement agencies to the unlawful act, combining punishment and admonishment. ${ }^{[6]}$ This mechanism provides legal basis for police to intervene in domestic violence. The mechanism has a deterrent effect on perpetrators, which may prevent the domestic violence from happening again. In accordance with Article20 of the Law ${ }^{(2)}$, the caution letter issued by the public security organ can be presented to the people's court and procuratorate as evidence of domestic violence. It provides a solid ground for police to intervene in the domestic violence and motivates them to deal with the domestic violence case.

\subsection{The Mechanism of Compulsory Reporting}

In accordance with the Law, Article 14 and Article $35^{3}$ provide that where any school, kindergarten, social work service institution, relief management institution, or welfare institution and the staff members thereof finds that a person without capacity for civil conduct or with limited capacity for civil conduct is likely to be inflicted on domestic violence, the entity or the individual should report to the public security organ immediately. It means that the organization or the individual aforesaid is obliged to report to the public security organ if they find the domestic violence happen.

\footnotetext{
(1) Anti-domestic Violence Law Article16:Where the domestic violence is not serious enough for public security administration punishment in accordance with the law, the public security organ shall criticize and educate the inflicter or issue a caution letter.The caution letter shall cover the inflicter's identity information, statements of facts of domestic violence, and content of prohibiting the inflicter from committing domestic violence, among others.

Article17: The public security organ shall send the caution letter to the inflicter and victim, and inform the residents' committee or villagers' committee. Residents' committees, villagers' committees and public security organs shall pay inspection visits to the inflicters who have received caution letters and the victims, and supervise the inflicters to ensure that they no longer commit domestic violence.

${ }^{2}$ Anti-domestic Violence Law Article20: When trying cases involving domestic violence, the people's courts may, based on such evidence as police records, caution letters and injury identification opinions of public security organs, find the facts of domestic violence.

${ }^{3}$ Anti-domestic Violence Law Article14:Where schools, kindergartens, medical institutions, residents' committees, villagers' committees, social work service institutions, relief management institutions, and welfare institutions and their staff members find in their work that persons with no or limited capacity for civil conduct are suffering or are suspected of suffering domestic violence, they shall report to public security organs in a timely manner. The public security organs shall keep confidential the information on informants.

Article 35 Where any school, kindergarten, medical institution, residents' committee, villagers' committee, social work service institution, relief management institution, or welfare institution and the staff members thereof fail to report the case to the public security organ in accordance with the provisions of Article 14 of this Law, which results in serious consequences, the competent authority at the higher level or the aforesaid entity itself shall punish the directly responsible persons in charge and other directly liable persons in accordance with the law.
} 
Because domestic violence is difficult to discover, the delayed reporting has been one of the important reasons that restricts judicial organs or administrative organs to intervene in the domestic violence in time. ${ }^{[7]}$ However, the compulsory reporting mechanism is an effective way to solve this issue. It exposes domestic violence to the public, protecting the rights of the disadvantaged persons without capacity for civil conduct or with limited capacity for civil conduct like juveniles, mental patients, and people with physical disability etc.

\subsection{Special Protection for Juveniles}

In Anti-domestic Violence Law, Article21 provides that a guardian shall assume legal liability if he/ she commits domestic violence. Where a guardian commits domestic violence which has seriously infringed the lawful rights and interests of the ward, the people's court may, upon the application of the relevant person or entity such as a close relative of the ward, residents' committee, villagers' committee, and the civil affairs department of the people's government at the county level, disqualify the guardian in accordance with the law, and designate a new guardian. The perpetrator whose guardianship is revoked shall continue to burden the appropriate alimony or medical fees for the victim. Although both Law of the People's Republic of China on the Protection of Minors and General Principles Of the Civil Law Of the People's Republic Of China involve the revoking of guardianship, it has no specific and detailed provision and cannot be implemented. Therefore, the provision of Anti-domestic Violence Law fills the void in the law system and provides the practical legal protection for minors.

\section{Conclusion}

Domestic violence infringes on the basic human rights and harms dignity. It may even increase the tension of the society, doing more harms to the individual, family, society or even the state. Because of that, it is important to prevent and bring the domestic violence under control. On March 1st, 2016, the enforcement of Anti-domestic Violence Law is of great significance to safeguard family members' rights and well being as well as the harmonious society. This law is momentous and reflects China's progress on its way improving laws. Yet, it is also noted that anti-domestic violence will be a long-term and arduous effort. Only if we make relentless efforts and keep implementing the Law, can we solve the domestic violence issue and foster harmony and stability in our family and society.

\section{Reference}

[1]Rui Shen, Research on the Legislation of Anti-domestic Violence in China, Anhui University(2016)

[2]Yilan Xia, An Analysis of the Party in the Concept of Domestic Violence,Collection of Women's Studies (2014)

[3]Xiaoqin Xie, Xiaoding Wang, A Study of Reasons of Women Inflicting on Domestic Violence, Review of Literature and History (2001)

[4]Liming Wang, Some Questions in the Amendment of Marriage Law, Law Science (2001)

[5]Yinlan Xia, The Law on Prevention and Punishment of Domestic Violence -With Focus on Institutional Constriction, Beijing: China Social Sciences Press (2011)

[6]Rui Shen, Research on the Legislation of Anti-domestic Violence in China, Anhui University(2016)

[7]Ninglan Xue, Academic interpretation of some provisions in Chinese anti-domestic violence law, Journal of Liaoning Normal University (Social Science Edition) ( 2017) 